\title{
Nitrosamines, Their Chemistries and Effects on Health
}

\author{
Sena Ozbay (Corresponding author) \\ Scientific and Technological Application and Research Center, \\ Aksaray University, Aksaray, Turkey \\ E-mail: sena_ozbay@hotmail.com \\ U. Tansel Sireli \\ Department of Food Hygiene and Technology, Faculty of Veterinary Medicine, \\ Ankara University, Ankara, Turkey \\ E-mail: utsireli@hotmail.com \\ Ayhan Filazi \\ Department of Pharmacology and Toxicology, Faculty of Veterinary Medicine, \\ Ankara University, Ankara, Turkey \\ E-mail: filazi@veterinary.ankara.edu.tr
}

\begin{abstract}
Meat and meat products, are one of the most important parts of a healthy and balanced diet. Also meat and meat products are accepted as a source of high biological value protein, B group vitamins, minerals and different bioactive compounds. Meat and meat products should be consumed for healthy life. But manufacturing process and products as a result of wrong practices and processes can become harmful to health. Especially processed and heat treated products are the main risk group.

Nitrosamines occuring during the production as a contaminant is defined as the amine derivatives containing $\mathrm{R}_{1} \mathrm{R}_{2} \mathrm{~N}-\mathrm{N}=\mathrm{O}$ functional group. Nitrosamine formation can occur in meat products with false and unconscious practice and can threat public health. Nitrosamine was reported as a carcinogenic to humans by the International Agengy For Research on Cancer. In this review, it is aimed to draw attention to the formation of nitrosamines in the meat matrix and their effects on health.
\end{abstract}

Keywords: Meat products, nitrosamine, carcinogenic.

DOI: $10.7176 / \mathrm{JSTR} / 5-4-13$

\section{Nitrozaminler, Kimyaları ve Sağlığa Etkileri}

\begin{abstract}
Özet
Et ve et ürünleri, sağlıklı ve dengeli bir diyetin en önemli parçalarından birini oluşturmaktadır. Aynı zamanda et ve ürünleri, yüksek biyolojik değerli proteinin, B grubu vitaminlerin, minerallerin ve farklı biyoaktif bileşiklerin kaynăğ olarak da kabul edilmektedir. Sağlıklı bir yaşam için tüketilmesi gereken et ve ürünleri, üretilirken yanlış uygulamalar ve bilinçsiz şekilde gerçekleştirilen işlemler sonucunda sağlığa zararlı bazı maddeler oluşabilmektedir. Özellikle işlenmiş ve ısıl işlem görmüş et ürünleri başlıca risk gruplarından birini oluşturmaktadır.

Et ve et ürünlerinde üretim sırasında oluşabilen sağlığa zararlı yapılardan birisi olan nitrozaminler, $\mathrm{R}_{1} \mathrm{R}_{2} \mathrm{~N}-\mathrm{N}=\mathrm{O}$ fonksiyonel grubunu içeren amin türevleri olarak tanımlanmaktadır. Nitrozamin oluşumu, yanlış ve bilinçsiz uygulamalarla et ürünlerinde oluşabilmekte ve halk sağlı̆̆ını tehdit etmektedir. Nitrozamin, Uluslararası Kanser Araştırmaları Enstitüsü tarafından insanlar için kanserojen olarak bildirilmiştir. Bu makalede nitrozaminlerin et matriksi özelinde gıdalarda oluşumu ve sağlığa etkileri konusunda dikkat çekilmesi amaçlanmıştır.
\end{abstract}

Anahtar Kelimeler: Et ürünleri, nitrozamin, kanserojen. 


\section{Giriş}

Taze et, yüksek su aktivitesine sahip, hızla bozulabilen bir gıdadır. Bu açıdan eti farklı ürünlere işlemek, raf ömrünü uzatmak ve yeni ürün geliştirmek açısından önem taşımaktadır. Türkiye'de sıklıkla tüketilen geleneksel ürünlerden sucuk ve pastırma ya da tüm dünyada da tüketilen sosis ve salam gibi ürünler, taze etin raf ömrünü uzatan alternatif et ürünleri olarak kabul edilirler. Üretim süreçleri ve katkı maddeleri yasalarda belirtildiği gibi gerçekleştirilen ürünlerde herhangi bir sağlık sorunu oluşmazken, yanlış uygulamalarla üretilen ya da tüketilen bu gibi kürlenmiş et ürünlerinde ciddi sağlık riskleri olduğu bilinmektedir. Çünkü bu durum, et ürünlerinde nitrozamin oluşması ihtimalini arttırmaktadır.

Bu bağlamda nitrat, nitrit ve nitrozamin kimyasını inceleyerek, sağlığa zararlı etkilerin oluşumu ve bu etkilerin sonuçlarının incelenmesi ve halk sağlığına dikkat çekmek amaçlanmıştır.

\section{Nitrat, Nitrit ve $\mathbf{N}$-Nitrozaminlerin Kimyası}

Nitrat doğada bol miktarda bulunan önemli bir iyondur. Nitrit ise nitratın indirgenmesi ile oluşmaktadır. $\mathrm{Bu}$ indirgenme süreci bakteriyel aktivite ile gerçekleşir. Nitrat varlığına oranla nitrit varlığı daha büyük bir risk yaratmaktdır. Çünkü oluşan nitrit özellikle yüksek sıcaklık ile ortam şartlarına da bağlı olarak nitrozamine dönüşebilmektedir (Byun ve ark., 2004). Ayrıca nitrit ile protein, karbonhidrat, lipid, katkı maddeleri ve tütsü bileşenleri arasında gıdaların işlenmesi ve depolanması aşamalarında birçok reaksiyon oluşabilmektedir (Özdestan ve Üren, 2010). Kısacası nitratın mikrobiyolojik etmenlerle nitrite indirgenmesi ve nitritin de aminler ve farklı bileşenlerle reaksiyona girerek toksik N-nitrozaminleri ya da değişken bileşikleri oluşturması büyük önem taşımaktadır.

Sularda ise N-nitrozamin oluşumu, reaktantlar, inhibitörler ve prekursörlerinin varlığ ile birçok reaksiyonun eş zamanlı olarak gerçekleşmesi gibi pek çok faktöre bağlıdır (Kadmi ve ark., 2015). Yapılan bir çok çalışmada nitrozaminlerin çevresel matrikslerde de oluştuğu bildirilmektedir (Rattray ve Cochran, 2014; Venkatesan ve ark., 2014; De Mey ve ark., 2017; Qiu ve ark., 2017; Gushgari ve ark., 2017).

Nitrat ve nitrit bileşikleri sadece kontrolsüz etkileşimlerle değil, ayrıca farklı endüstri kollarında teknolojiye yardımcı kimyasallar olarak bilinçli bir şekilde et ürünlerine katılmak suretiyle de kullanılmaktadır. Ancak en çok kullanıldığı sektörlerden birisi gıda sektörüdür. Günümüz gıda tüketim alışkanlıklarının değişimi ve artan nüfus, gıdaların raf ömrünün uzatılması için yeni kimyasalların ve teknolojilerin kullanımı da nitrozamin oluşumu açısından riski arttırmaktadır.

Basitçe nitrozaminler, $\mathbf{R}_{\mathbf{1}} \mathbf{R}_{\mathbf{2}} \mathbf{N}-\mathbf{N}=\mathbf{O}$ fonksiyonel grubuna sahip amin türevleri olarak tanımlanırlar (Yuan ve ark., 2015). Ancak nitrozaminler, prekürsörler veya inhibitörlerin varlığından etkilenen, nitrit ve aminler arasındaki bir dizi kompleks reaksiyon sonucunda oluşmaktadır. Nitrozamin oluşumu, nitrit ile amino grubu içeren yapıların reaksiyonu sonucunda ikincil veya üçüncül aminlerin bir nitrolama (bir moleküle nitro kökü katmak için yapılan işlem) maddesi ile (azot oksitleri veya nitrat tuzları gibi) reaksiyonu sonucu oluşurlar. Şekil 1.'de oluşum mekanizması gösterilmektedir.

Şekil 1.'de de görüldüğü gibi birincil aminler hızla alkol $(\mathrm{ROH})$ ve azota $\left(\mathrm{N}_{2}\right)$ dönüşürken, sadece ikincil aminler stabil nitrozamin oluşumunu gerçekleştirebilmektedir (Honikel, 2008). İkincil aminler ya da amidler, nitrolama maddesi ile reaksiyona girerek, $\mathbf{R}_{\mathbf{1}} \mathbf{R}_{\mathbf{2}} \mathbf{N}-\mathbf{N}=\mathbf{O}$ fonksiyonel grubuna sahip nitrozaminleri oluşturmaktadır. İkincil aminlerin gerçekleştirdiği nitrozamin oluşumu reaksiyonu Şekil 2.'de gösterilmiştir.

Şekil 2.'de görülen Y-NO bir nitrolama maddesidir. Bu maddenin Y maddesi ile etkinliğinin değişebileceği, buna bağlı olarak da nitrozamin oluşumunun artıp azalabildiği bilinmektedir (Douglass ve ark., 1978). Nitrolama maddesinin varlığı dışında bu reaksiyona etki eden pişirme süresi, sıcaklığı ve yöntemi, mikrobiyal flora, ortam sıcaklığı, ortamdaki kalıntı ya da eklenen nitrit miktarı, nitrozamin prekursörlerinin konsantrasyonu, tuz konsantrasyonu ve $\mathrm{pH}$ gibi birçok faktörün daha bulunduğu bildirilmiştir. Nitrozamin oluşumu ayrıca, ortamdaki aminlerin yapısına, reaktiflerin ve bazı inorganik iyonların konsantrasyonuna, nitrit/amin oranına ve depolama şartlarına bağlı olarak da değişebilmektedir (Yurchenko ve Mölder, 2007; Honikel, 2008; Herrmann ve ark., 2015a; Wang ve ark., 2015; Mejborn ve ark., 2019).

Kimyasal olarak N-nitrozaminler, uçucu ve uçucu olmayanlar olarak iki sınıfta incelenirler. İşlenmiş et ürünlerinde uçucu olmayan nitrozamin seviyeleirnin uçucu nitrozamin seviyesinden daha yüksek olduğu bildirilmekle birlikte (Herrmann ve ark., 2015b) genelde uçucu N-nitrozaminlerin tüketimleri ile kanser oluşumu ilişkisi dikkat çekmektedir. Halk sağlığı üzerine yoğunlaşan bu endişeler ve buna bağlı olarak kimyasal yapıları, reaksiyonları ve vücuda etkileri konusunda çalışmaların sayısı artarken, nitrozaminler, uçucu ve uçucu olmayan çeşitlerine ek olarak kanserojen etkilerine göre de sinıflandırılmaya 
başlanmıştır. Örneğin yapılan çalışmalarda N-nitrosodimethylamine (NDMA), N-nitrosodiethylamine (NDEA), N-nitrosodi-n-butylamine (NDBA), N-nitrosopiperidine (NPIP) ve N-nitrosopyrrolidine (NPYR) özellikle kanserojen ve muhtemel kanserojen uçucu nitrozamin çeşitleri olarak karşımıza çıkmaktadırlar (Yuan ve ark., 2015). Amerika Birleşik Devletleri Çevre Koruma Örgütü (EPA) bu beş nitrozamine ek olarak N-Nitrosodi-n-propylamine (NDPA) ve N-Nitrosomethylethylamine (NMEA) tiplerini de incelemiş özellikle NDMA ve NDEA tiplerinin kanserojen etkisine vurgu yapmıştır (Anon, 2011).

Ciddi sağlık riskleri barındıran N-nitrozaminlerin gıdalardaki oluşum mekanizması da özellikle oral yolla $\mathrm{N}$-nitrozaminlere maruz kalınması ve vücuttaki toksik etkisi nedeniyle derinlemesine incelenmelidir. Çünkü bu mekanizmanın anlaşılması, gıdalarda ve özellikle risk grubu olan et ve et ürünlerinde Nnitrozamin seviyelerinin düşürülmesi, sağlıklı ve besleyici değeri yüksek et ürünlerinin üretilebilmesi açısından büyük önem taşımaktadır.

\subsection{Gldalarda Nitrozamin Oluşumu}

Pek çok farklı kaynaktan nitrozaminlere maruz kalmamıza rağmen en temel kaynakların başında gıdaların geldiği bilinmektedir (Gushgari ve Halden, 2018). Gıda ürününün hijyeni, aroması, tekstürü, rengi ve lezzetine katkıda bulunan kimyasallar olması nedeni ile nitrat ve nitrite gıda üretiminde ihtiyaç duyulmaktadır (Park ve ark., 2015). Bu önemli avantajlarına rağmen sağlığa olan etkilerinden dolayı kullanımları yarar-zarar ekseninde hala tartışılmaktadır Bu durum, nitrat ve nitritin kürlemede miktarının azaltılması ya da tamamen elimine edilmesi gerekliliğini doğurmuştur (Marriott ve ark., 1981). Ancak yapılan çalışmalar, işlenmiş et ürünlerinin sebzelerden daha düşük düzeylerde nitrat-nitrit içerdiğini göstermektedir. Vücuda alım açısından değerlendirdiğimizde ise günlük alınan nitrat miktarının büyük bir oranının sebze kaynaklı olduğu, bir kıyaslama yapıldığı durumda ise işlenmiş et ürünlerinden alınan nitrat-nitrit miktarının, sebzelerden alınan miktardan çok daha az olduğu bilinmektedir (Honikel, 2008). Hatta insan vücudunda üretilen nitrat ve nitritin tüm bu gıdalardakinden de fazla miktarda olduğu ifade edilmektedir (Archer, 2002).

Kısacası nitrat ve nitrit gıdalarda üç yolla bulunabilmektedir;

- Gıdaların yapısında doğal olarak nitrat, nitritin bulunması

- Suda bulunan nitrat ve nitritin üretim sürecinde gıdaya dahil olması

- Katkı maddesi olarak ilave edilmesi (bazı et ürünleri, beyaz peynir vb)

İşlenmiş gıda ürünleri incelendiğinde ise bu ürünlerin, nitrat-nitritten ziyade, N-nitrozaminleri bulundurması açısından risk taşıdıkları bilinmektedir. Yapılan son çalışmalar ile farklı kimyasal reaksiyonlar sonucunda insan gastro-intestinal sistminde de nitrozaminlerin oluşabileceği bildirilmiştir (De La Pomélie ve ark., 2018). Nitrozaminlerin genel olarak kür edilmiş etlerde, peynir ve balıkta yüksek düzeylerde oluştuğu bildirilmiştir (Österdahl, 1988). Genelde işlenmiş et ve et ürünlerinde görülen Nnitrozaminlerin düşük düzeylerde dahi olsa peynir altı suyu tozunda (Oliveira ve ark., 1995) ve bitkisel yağlarda da (Yurchenko ve Mölder, 2006) bulunduğu tespit edilmiştir. Ayrıca pirinç çorbası, mısır yağı ve elma suyu gibi tarımsal kaynaklı işlenmiş gıdalarda da nitrozamin tespit edilmiştir (Seo ve ark., 2016). Ancak tüm bu gıdalar içerisinde en önemli nitrozamin kaynaklarını işlenmiş et ürünleri oluşturmaktadır. Bu et ürünleri üretimi açısından da kürleme prosesi önem taşımaktadır.

Nitrozamin oluşum sürecini etkileyen birçok faktör vardır. Örneğin mikroorganizmalar, gıdalarda nitrozamin oluşumunda nitratı nitrite indirgeyerek ve proteinleri de amin ve amino asitlere parçalayarak oluşum sürecinde kilit bir rol üstlenebilmektedir. Mikroorganizmalara ek olarak teknolojik işlemler de nitrozamin oluşumunu tetiklemektedir. Örneğin pişirme teknolojisi, süresi ve sıcaklığının süreci doğrudan etkilediği bilinmektedir. Li ve ark., (2012) yaptıkları çalışma ile kızartmanın sosiste, haşlama ya da mikrodalga uygulamasına nazaran daha yüksek oranda nitrozamin oluşumuna sebep olduğunu göstermişlerdir.

\subsection{Et Ürünlerinde Nitrozamin Oluşumu}

Et muhafaza yöntemleri, coğrafyaya bağlı olarak değişkenlik gösterir örneğin Akdeniz Bölgesi'nde et genelde kurutma ve tütsüleme ile ürüne işlenirken Avrupa'da ise, et muhafaza yöntemi olarak tütsüleme ve fermantasyon gibi yöntemler daha yaygın kullanılmaktadır (Toldra ve Hui, 2014). Bu yöntemler, hem etin raf ömrünü uzatmayı hem de yeni et ürünlerinin oluşumunu sağlamaktadır. Ancak IARC'a göre Nnitrozo bileşenlerin vücuda alınmasında temel kaynak olarak kürlenmiş ürünler görülmekte (IARC, 2010) ve bu açıdan özellikle kürlenmiş et ürünleri riskli gıdalar olarak kabul edilmektedir.

Nitrat ve nitritin neden olabileceği sağlık risklerine rağmen kürleme sürecinde kullanımlarının önemli teknolojik sebepleri bulunmaktadır. Ö̈zellikle kürlenmiş et ürünlerinin, sahip olması beklenen rengi sağlaması, nitritin et kürlemede kullanımının temel nedeni olduğu ifade edilmektedir (Horsch, 2013). İkinci en önemli sebep ise, bu bileşenlerin antimikrobiyal etkisidir. Özellikle nitrit, C. botulinum'a karş1 
etkin olduğu için kürlemede önemli bir ajan olarak da kabul edilmektedir (Archer, 2002). Bu amaçla kürlenmiş et ürünlerine katılan nitrit;

- Nitrit ve bileşikleri hücre içi enzimleri yükseltgeyerek veya indirgeyerek,

- C. botilinum için gerekli olan Fe ve diğer metalleri bağlayarak,

- Hücre membranı ile reaksiyonları sonucu maddelerin taşınmasını ve metabolik değişimleri kısıtlayarak Clostridium botilinum gelişimini inhibe etmektedir.

Nitrit genel olarak $C$. botulinum'u inhibe etmek amacıyla kullanılmasına rağmen etki alanı geniştir. Nitritin hem gram pozitif hem de gram negatif mikroorganizmalar için uygun bir antimikrobiyal olduğu bilinmektedir (Horsch, 2013). C. perfringens, Bacillus. cereus, Staphylococcus aureus ve Salmonella spp üzerinde de inhibe edici etkisi bulunmaktadır (Anar, 2015). Tek başına kullanımının dışında her antimikrobiyal uygulama gibi nitritte de bütünleşik yöntemler antimikrobiyal etkiyi arttırmaktadır. Tuz, 1sıl uygulamalar ve etin başlangıçtaki kalıntı nitrit seviyesi (Archer, 2002), oksijen ve ışınlama gibi etmenler de nitritin mikroorganizmalar üzerindeki etkinliğini değiştirmektedir (Öztürk ve ark., 2015). Kısacası et ürünlerinde nitrat ve nitritin temel fonksiyonları aşağıdaki şekilde sıralanabilir;

- Bakterisit etki ile antimikrobiyal etkinlik göstermek ve özellikle $C$. botulinum'un gelişimini önlemek,

- Geleneksel, arzu edilen kırmızı - pembe renk ile aroma oluşumunu sağlamak,

- Bir antioksidan olarak davranmak ve et ürününün tat, koku ve aromasını arttırmak ve bunların stabilitesini sağlamak (Honikel, 2008; Horsch, 2013; Anar, 2015),

- Bu faydalara dolaylı bir katkı olarak kürlenmiş et ürünlerinde meydana gelen düşük molekül ağılıklı nitrozaminlerin de ürünün aroması açısından önem taşıdığı bildirilmektedir (Paralori, 1996).

Nitrat ve nitrit bu gibi faydalarına rağmen N-nitrozamin oluşumu açısından risk yaratan katkı maddeleridir. Özellikle isıl işlemlerle et ürünlerinin nitrozamin seviyeleri yükselmektedir. Ancak nitrozamin oluşumu çok kompleks ve birçok farklı faktörden etkilenen bir reaksiyonlar dizisinin bir sonucudur. Isıl işlem uygulamaları (pişirme süresi, şekli ve sıcaklık) büyük oranda süreci etkilemekle birlikte (Yurchenko ve Mölder, 2007), nitrozamin oluşumu için, nitrat, nitrit, birincil, ikincil ve üçüncül dereceden aminler, amidler, proteinler, peptitler, aminoasitler, farklı prekürsörler ve mikrobiyal aktivite gerekmektedir (Yurchenko ve Mölder, 2007). Et matriksinde yer alan prolinin, nitrozamin oluşumunda önemli bir prekursör olduğu ancak hidroksiprolinin tam tersi şekilde NPYR (N-nitrosopirrolidin) oluşumunu inhibe ettiği bildirilmiştir (Drabik-Markiewicz ve ark., 2009). Görüldüğü gibi ortamda inhibitör varlığı (Fiddler ve ark., 1978), kalıntı olan ya da eklenen nitrit konsantrasyonuna ve depolama şartlarına bağlı olarak da et ürünlerindeki nitrozamin miktarını değiştirmektedir (Yurchenko ve Mölder, 2007). Drabik-Markiewicz ve ark. (2011) nitrozamin oluşumunun nitrit miktarı, işlem sıcaklığ ve ortamda bulunan biyojen aminlerin varlığ ile ilişkisini domuz pastırmasında tespit etmişlerdir.

Nitrozamin oluşumuna etki eden diğer etmenlerden tiyosiyanat iyonunun, nitrozamin oluşumunu hızlandırdığı ancak askorbik asit ve tuzları ile tokoferol gibi maddelerin bu oluşumu engellediği bildirilmiş̧ir (Marriott ve ark., 1981; Rywotycki, 2002). Askorbik asitin, özellikle kürlenmiş et ürünlerindeki varlığı ile nitritin, nitrik okside indirgenmesini sağlayarak depolama sürecinde de nitrit miktarının aşamalı olarak düşmesini sağladığı bilinmektedir (Li ve ark., 2013). Askorbik asit de kullanıldığ durumlarda büyük oranda $(\% 20-\% 75)$ kürlenmiş et ürünlerinde nitrozamin seviyesini düşürebilmektedir (Herrmann ve ark, 2015a). Oluşumu azaltan bu etmenlerin yanı sıra kürlemenin, polifosfatlarla yapılmasının da nitrozamin oluşumunu arttırdığı, yapılan çalışmalarla gösterilmiştir (Rywotycki, 2002).

Sadece kimyasal yapılar değil teknolojik işlemler, ambalajlama yöntemleri ve depolama şartları da Nnitrozamin oluşumuna etki etmektedir. Örneğin ışınlama ile et ürünlerinde nitrozamin miktarının düşürüldüğü (Byun ve ark., 2004), gama ışınlarının, miktarın düşürülmesinde etkin olduğu da bildirilmiştir (Rabie ve ark., 2010). Işınlamada, yöntemin uygulanma biçimine bağlı olarak nitrozamin oluşumunun minimize edilebildiği de yapılan çalışmalarla gösterilmiştir (Jo ve ark., 2003). Işınlama işlemi özellikle depolama sürecindeki nitrozamin oluşumunu azaltıcı bir etki göstermektedir. Gama ışınları kullanılarak ışınlanmış sosislerin $4{ }^{\circ} \mathrm{C}$ 'de 4 hafta boyunca depolanması sonucunda, ışınlama uygulanmayan örneklere göre nitrozamin miktarının daha düşük seviyede olduğu tespit edilmiştir. (Ahn ve ark., 2002). Aynı çalışmada nitrozamini düşürmek için farklı yöntemlerle, ışınlamanın bir arada kullanılmasının daha iyi sonuçlar verdiği belirtilmiştir. Farklı bir çalışmada aynı depolama şartları (4 ${ }^{\circ} \mathrm{C}$ 'de 4 hafta) kullanılarak benzer sonuçlar elde edilmiş, 5,10 ve $20 \mathrm{kGy}$ enerji değerleri ile sosisler ışınlanmış ve bu ürünlerin depolama süreci sonunda N-nitrozopirrolidin (NPYR) ve Nnitrozodimetilamin (NDMA) oluşumlarının ışınlama ile düştüğü bildirilmiştir (Byun ve ark., 2004). Böylece sadece ortamdaki kimyasal yapıların miktarını değiştirmek yerine farklı teknolojik yöntemlerle de nitrozamin oluşumu etkin bir şekilde düşürülebilmektedir. Özellikle 1şıllama gibi uygulamalarla 
mikrobiyal aktivitenin minimize edilmesi sağlanmaktadır. Bu durum da depolama sürecinde mikrobiyal aktivite ile tetiklenen nitrozamin oluşumunu büyük ölçüde düşürmektedir.

Ambalajlamanın da mikrobiyal aktivite ve dolayısıyla nitrozamin seviyesi ile bir ilişkisi bulunmaktadır. Jo ve ark. (2003) yaptıkları çalışmada $\mathrm{CO}_{2}$ ile ambalajlanmış sosislerde aerobik veya vakum ortama göre en düşük nitrozamin oluşumu olduğunu bildirmişlerdir. Başka bir çalışmada ise vakum paketlemenin aerobik paketlemeye kıyasla nitrozamin oluşumu açısından üstünlüklerine vurgu yapılmıştır (Ahn ve ark., 2002). Song ve ark., (2003) yaptıkları çalışmada farklı atmosfer koşulları ile paketleme $\mathrm{CO}_{2}(100 \%)$, $\mathrm{N}_{2}(100 \%)$, and $\mathrm{CO}_{2} / \mathrm{N}_{2}(25 \% / 75 \%)$ ve farklı seviyelerde gama ışınlamanın $0,5,10$ ve $20 \mathrm{kGy}$ nitrozamin oluşumuna etkilerini incelemişlerdir. Bu araştırmanın bir sonucu olarak modifiye atmosfer ile ışınlama uygulamasının bir arada yapılmasının, sosislerde nitrozamin miktarını düşürdüğünü bildirmişlerdir.

İşlenmiş et ürünlerinin yukarıda belirtilen tüm bu nedenlerden dolayı önemli bir risk oluşturabileceği bilinmektedir. Ancak Rywotycki (2003) yaptığı çalışmada çiğ etteki N-nitrozamin miktarın araştırmış, hayvan türünün, beslenme biçiminin hatta mevsimin bile çiğ etteki nitrozamin seviyesini değiştirdiğini bildirmiştir. $\mathrm{Bu}$ durum herhangi bir işleme tabi tutulmamış ette de nitrozamin oluşabildiğini göstermektedir. Tüm dünyada sosis, nitrozaminler açısından en önemli et ürünü olarak görülmektedir. Ancak Türkiye'de de özellikle geleneksel olarak tüketilen döner ve sucuklarda nitrozamin oluştuğu da bildirilmiştir (Ozel ve ark., 2010).

\subsection{Nitrozaminlerin Sağlı̆̆a Etkileri}

Nitrozaminlerin oluşumunda önemli bir yer tutan nitratın akut toksisitesine pek sık rastlanılmamaktadır. Bu hususta skklıkla karşıllaşılan sağlık sorunları, doğrudan nitritle ya da nitratın nitrite indirgenmesi sonucu ortaya çıkmaktadır.

Yetişkinlerde 8-15 g sodyum ya da potasyum nitrat tüketimini takiben şiddetli gastroenterit, karın ağrısı, idrar ve gaitada kan ve kişide halsizlik bulguları tespit edilmiş̧ir. Nitritin ise daha düşük seviyelerde dahi nitrata göre daha toksik olduğu bilinmektedir. Oral yoldan nitrit alımında sıçanlarda öldürücü doz-50 (LD ${ }_{50}$ )'nin 100-200 mg/kg olduğu bildirilmiştir (Lundberg ve ark., 2011). Bu toksisite seviyelerinden de anlaşılacağı gibi akut nitrit toksisite vakalarına çok daha sık rastlanmakta ve bu toksisiteye bağlı ölüm vakaları yaşandığı da bilinmektedir (Özdestan ve Üren, 2010). Bu durumun sebebi, akut nitrit toksisitesinde, nitritin kandaki hemoglobin ile hızla reaksiyona girerek oksijen taşıma yeteneğine sahip olmayan methemoglobin oluşturması ile açıklanmaktadır (Lundberg ve ark., 2011).

Doğal kimyasal yapılar olan nitrat ve nitritin sadece memeli vücudunda değil daha önce bahsedildiği gibi sebze, su ve toprakta bol miktarda bulunduğu bilinmektedir. Günlük gıda tüketiminin nitrit toksisitesine yol açmamasının nedeni, günlük yeterli miktarda vitamin $\mathrm{C}$ alımının, bu yolla meydana gelen intragastrik nitrozlama sürecini önlemesinden kaynaklanmaktadır (Mirvish, 1986). Ayrıca McKnight ve ark., (1997) nitratın, bir dizi reaksiyon sonucunda, mide patojenleri açısından koruma sağladığını bildirmişlerdir. Bu yapıların vücuda farklı faydaları da bulunmaktadır;

- Nitrik oksit, kan basıncının ve akışının dengelenmesinde (Bryan ve Hord, 2010) ve bağışıklık sistemi, yaraların iyileşmesi ve sinir sisteminin regülasyonunda (Archer, 2002) olumlu bir rol oynamaktadır,

- Nitrat, oksijen döngüsünü arttırarak fiziksel performansın yükselmesini sağlamaktadır (Larsen ve ark., 2010),

- Özellikle pH ile sinerjistik etki yaratarak vücutta enterik patojenler üzerine etki etmektedirler (Y. Enterocolitica, Salmonella Enteritidis, Shigella sonnei, E. Coli O157) (Archer, 2002).

Ancak nitrat ve nitritin kullanımları ile oluşan nitrozaminlerin yarattığı sağlık riskleri, halk sağlığ açısından yetkili otoritelerde endişelere neden olmaktadır. Nitrozaminin să̆lığa olumsuz etkilerinin ortaya çıkarılması, 1950'li yıllarda, nitrozamin ile kanser ilişkisinin ilk kez gündeme gelmesiyle anlaşılmıştır. Bu durum bir vizon çiftliğinde nitrit bulunan yemlerle beslenen vizonlarda, yüksek sayıda tümör oluşumu ile başlamıştır. Bu gerçekle birlikte yapılan çalışmalarla nitrozamin ve tümör gelişimi arasındaki bağlantı görülmüştür (Horsch, 2013).

Sonrasında deney hayvanlarında yapılan çalışmalarda, sıçanlar, fareler ve hamsterlarda, nitrozaminlerin, karaciğer, özafagus, böbrekler, burun boşluğu ve pankreasta tömörlere neden olduğu görülmüştür (Mirvish, 1986). Farklı çalışmalarda da, bu durumu destekleyen sonuçlar elde edilmiştir. 300'den fazla nitrozaminin, yaklaşık \%90'ının deney hayvanlarında kanserojen etki gösterdiği bildirilmiştir. Gelişmiş primatlar da dâhil olmak üzere 40 deney hayvanı türünün değişik organlarında, nitrozaminlerin, kanser oluşturma potansiyeli de belirlenmiştir (Anar, 2015). Böylece IARC, nitrozaminleri insanlar için de kanserojen olarak tanımlamışır (IARC, 1987). Demeyer ve ark., (2008) yaptıkları epidemiyolojik çalışma ile, özellikle kolorektal kanser ile işlenmiş et ürünleri tüketimi arasında ilişsi olduğunu göstermişir. Bulushi ve ark., (2009) da tuzlanmış, kürlenmiş ve kurutulmuş balıketi tüketimi ile mide kanseri arasında pozitif bir ilişki olduğunu bildirmişlerdir. Hatta doğrudan nitrozamin alımına bağlı 
olmaksızın, gıdalar ile nitrozamin öncüllerinin alımının dahi idrar kesesi kanseri riskini arttırabileceği gösterilmiştir (Wilkens ve ark., 1996). Nitrozaminlerin ispatlanmış kanserojen etkilerine rağmen her birey ve dozda aynı toksik etkiyi beklemenin doğru olmadığı, nitrozaminlerin sağlığa etkileri açısından dozlarının ve bireysel farklılılıların büyük önem taşıdığı, uçucu nitrozaminlerin insan sağlığı açısından tolere edilebilen düzeylerinin 5-10 $\mu \mathrm{g} / \mathrm{kg}$ vücut ağırlı̆̆ı olduğu belirlenmiştir (Campillo ve ark., 2011). Çevresel matrikslerde nitrozamin oluşumu ile kanser arasında korelasyon olduğu da çeşitli çalışmalarda bildirilmiştir (Stepanov ve ark., 2014; Fritchi ve ark., 2015; Gankhuyag ve ark., 2017; Kao ve ark., 2017). Kanserojen etkilerinin yanı sıra nitrozaminler, mutajenik ve teratojenik etkiler de göstermektedir (Hotchkiss 1987). Bununla beraber Blot ve ark. (1999), yaptıkları çalışmada hamilelik döneminde kürlenmiş et tüketimi ile çocuklarda herhangi bir kanser türünde pozitif ya da negatif bir etkileşimin olmadığını bildirmişlerdir.

Nitrozamin - kanser ilişkisi birçok çalışma ile gösterilmiştir. Bu açıdan nitrozamin alınmının en temel yap1 taşı olan işlenmiş et ürünleri (özellikle kürlenmiş) et seçiminden, üretimine, ambalajlamadan tüketimine kadar önem taşımaktadır. Hatta tüketici tarafından satın alınan ürünlerin ne şekilde pişirilip, depolanarak tüketileceği de bu ürünlerin halk sağlığına etkileri açısından doğru değerlendirilmelidir. Riskleri ve oluşum aşamalarını bilerek buna uygun bilinçle üretim ve tüketim süreçlerini gerçekleştirmek bu tip gıdalardan gelebilecek sağlık risklerini bertaraf ederek endişeleri ortadan kaldıracaktır. Bu açıdan Türkiye'de ve dünyada yapılan deneysel çalışmalar baz alınarak hazırlanan yasal sınırlar ve bunlara uyulması büyük önem taşımaktadır.

\section{Sonuç ve Tartışma}

Nitrat ve nitrit hem doğada yaygın olarak bulunmakta hem de katkı maddesi uygulamaları ile gıda sektöründe sıklıkla kullanılmaktadır. Ancak bu yapıların ortamdaki varlıklarının, ortam şartları ile etkileşimi sonucunda çeşitli matrikslerde bir dizi reaksiyon neticesinde N-nitrozaminlerin oluşumuna sebep olduğu bilinmektedir.

$\mathrm{N}$-nitrozaminlerin varlığı ve bu kimyasal yapıların varlığı ile ilişkilendirilen kanserojen etki, gıdaların, üretim, ambalajlama, depolama ve tüketim süreçlerine dikkat çekmektedir. N-nitrozaminler açısından risk oluşturan özellikle kürlenmiş gıdalar (et ürünleri, peynir vb.) sağlık endişeleri çerçevesinde önem taşımaktadır.

Sağlıklı beslenmek için satın alınan herhangi bir gıda maddesinden zararlı etki görmeyi hiçbir tüketici tercih etmez. Bu açıdan risk grubunu oluşturan gıdaların tüketimleri ile ilgili yarar-zarar ekseninde çalışmalar arttırılmalıdır. Ayrıca bu tip ürünlerin üretimlerinde kullanılan kürleme tuzları, ürün formülasyonları, üretim şartları, 1sıl uygulama yöntem ve süreleri gözden geçirilmeli, en sağlıklı optimal şartların geliştirilmesine önem veilmelidir. Bunlara ek olarak depolama ve tüketim aşamalarında yalnız olan tüketicinin bu konuda bilinçlendirilmesi de büyük önem taşımaktadır. Tüm gıda üretim süreçleri için sağlıklı, alternatif katkı maddeleri üzerine yenilikçi araştırma-geliştirme çalışmalarının yararlı olacağı düşünülmektedir. Günümüz şartları açısından ise bu kimyasalların kullanımının en düşük seviyelere çekilmesi, yasalara uygun üretim yapılması, üretim süreçleri ve 1 sıl işlem parametrelerinin kontrol altında tutulmasının büyük avantajlar sağlayacağı öngörülmektedir.

\section{Kaynaklar}

Ahn, H. J., Jo, C., Kim, J. H., Chung, Y. J., Lee, C. H., Byun, M. W. (2002). Monitoring of nitrite and N-nitrosamine levels in irradiated pork sausage. Journal of food protection, 65(9), 14931497.

Anar, Ş. (2015). Et ve et ürünleri teknolojisi (3.baskı). Bursa: Dora Basım-Yayın Dağııım Ltd. Şti., ISBN 978-605-9929-66-0

Anon. (2011). Environmental Guidelines and Regulations for Nitrosamines: A Policy Summary Final Report [Revision 2].

Archer, D. L. (2002). Evidence that ingested nitrate and nitrite are beneficial to health. Journal of Food Protection, 65(5), 872-875.

Blot, W. J., Henderson, B. E., Boice Jr, J. D. (1999). Childhood cancer in relation to cured meat intake: review of the epidemiological evidence. Nutrition and cancer, 34(1), 111-118. 
Bryan, N. S., Hord, N. G. (2010). Dietary nitrates and nitrites: the physiological context for potential health benefits. Food, Nutrition and the Nitric Oxide Pathway: Biochemistry and Bioactivity. NS Bryan, ed. DESTech Publications Inc., Lancaster PA. In Horsch, A. M. (2013). The effect of pH and nitrite concentration on the antimicrobial impact of celery juice compared with sodium nitrite on Listeria monocytogenes (Doctoral dissertation, Iowa State University).

Byun, M. W., Ahn, H. J., Kim, J. H., Lee, J. W., Yook, H. S., Han, S. B. (2004). Determination of volatile $\mathrm{N}$-nitrosamines in irradiated fermented sausage by gas chromatography coupled to a thermal energy analyzer. Journal of Chromatography A, 1054(1), 403-407.

Bulushi, I. A., Poole, S., Deeth, H. C., Dykes, G. A. (2009). Biogenic amines in fish: roles in intoxication, spoilage, and nitrosamine formation-a review. Critical reviews in food science and nutrition, 49(4), 369-377.

Campillo, N., Vinas, P., Martínez-Castillo, N., Hernández-Córdoba, M. (2011). Determination of volatile nitrosamines in meat products by microwave-assisted extraction and dispersive liquidliquid microextraction coupled to gas chromatographymass spectrometry. Journal of Chromatography A, 1218 (14), 1815-1821.

Demeyer, D., Honikel, K., De Smet, S. (2008). The World Cancer Research Fund report 2007: A challenge for the meat processing industry. Meat science, 80(4), 953-959.

De Mey, E., De Maere, H., Paelinck, H., \& Fraeye, I. (2017). Volatile N-nitrosamines in meat products: Potential precursors, influence of processing, and mitigation strategies. Critical reviews in food science and nutrition, 57(13), 2909-2923.

De La Pomélie, D., Santé-Lhoutellier, V., Sayd, T., \& Gatellier, P. (2018). Oxidation and nitrosation of meat proteins under gastro-intestinal conditions: Consequences in terms of nutritional and health values of meat. Food chemistry, 243, 295-304.

Douglass, M. L., Kabacoff, B. L., Anderson, G. A., Cheng, M. C. (1978). The chemistry of nitrosamine formation, inhibition and destruction. J. Soc. Cosmet. Chem, 29(9), 581-606.

Drabik-Markiewicz, G., Dejaegher, B., De Mey, E., Kowalska, T., Paelinck, H., Vander Heyden, Y. (2011). Influence of putrescine, cadaverine, spermidine or spermine on the formation of $\mathrm{N}$ nitrosamine in heated cured pork meat. Food chemistry, 126(4), 1539-1545.

Drabik-Markiewicz, G., Van den Maagdenberg, K., De Mey, E., Deprez, S., Kowalska, T., Paelinck, H. (2009). Role of proline and hydroxyproline in $\mathrm{N}$-nitrosamine formation during heating in cured meat. Meat science, 81(3), 479-486.

Fiddler, W., Pensabene, J. W., Piotrowski, E. G., Phillips, J. G., Keating, J., Mergens, W. J., Newmark, H. L. (1978). Inhibition of formation of volatile nitrosamines in fried bacon by the use of cure-solubilized. alpha.-tocopherol. Journal of agricultural and food chemistry, 26(3), 653656.

Fritschi, L., Benke, G., Risch, H. A., Schulte, A., Webb, P. M., Whiteman, D. C., ... \& Neale, R. E. (2015). Occupational exposure to $\mathrm{N}$-nitrosamines and pesticides and risk of pancreatic cancer. Occup Environ Med, 72(9), 678-683.

Gankhuyag, N., Lee, K. H., \& Cho, J. Y. (2017). The role of Nitrosamine (NNK) in breast cancer carcinogenesis. Journal of mammary gland biology and neoplasia, 22(3), 159-170. 
Gushgari, A. J., \& Halden, R. U. (2018). Critical review of major sources of human exposure to Nnitrosamines. Chemosphere.

Gushgari, A. J., Halden, R. U., \& Venkatesan, A. K. (2017). Occurrence of N-nitrosamines in US freshwater sediments near wastewater treatment plants. Journal of hazardous materials, 323, 109115 .

Herrmann, S. S., Duedahl-Olesen, L., \& Granby, K. (2015b). Occurrence of volatile and non-volatile $\mathrm{N}$-nitrosamines in processed meat products and the role of heat treatment. Food Control, 48, 163169.

Herrmann, S. S., Granby, K., Duedahl-Olesen, L. (2015a). Formation and mitigation of Nnitrosamines in nitrite preserved cooked sausages. Food chemistry, 174, 516-526.

Honikel, K. 2008. The use and control of nitrate and nitrite for the processing of meat products. Meat Science, 78(1-2), 68-76.

Horsch, A. M. (2013). The effect of pH and nitrite concentration on the antimicrobial impact of celery juice compared with sodium nitrite on Listeria monocytogenes (Doctoral dissertation, Iowa State University).

Hotchkiss, J. H. (1987). A review of current literature on N-nitroso compounds in foods. Advances in food research (USA).

IARC. (1987). Overall evaluation of carcinogenicity: anupdating of IARC monographs. Vols. 1-42, Suppl. 7, Monographs on the Evaluation of the Carcinogenic Risk of Chemicals to Humans. International Agency for Research on Cancer, Lyon.

IARC. (2010). IARC Monographs on the Evaluation of Carcinogenic Risks to Humans. Vol. 94, Ingested Nitrate and Nitrite, and Cyanobacterial Peptide Toxins. International Agency for Research on Cancer, Lyon.

Ikeda, K., Migliorese, K. G. (1990). Analysis of nitrosamines in cosmetics. J. Soc. Cosmet. Chem, 41(5), 283-333.

Jo, C., Ahn, H. J., Son, J. H., Lee, J. W., Byun, M. W. (2003). Packaging and irradiation effect on lipid oxidation, color, residual nitrite content, and nitrosamine formation in cooked pork sausage. Food Control, 14(1), 7-12.

Kadmi, Y., Favier, L., Wolbert, D. (2015). N-nitrosamines, emerging disinfection by-products of health concern: an overview of occurrence, mechanisms of formation, control and analysis in water. Water Science and Technology: Water Supply, 15(1), 11-25.

Kao, Y. L., Kuo, Y. M., Lee, Y. R., Chen, W. J., Lee, Y. S., \& Lee, H. J. (2017). Apple polyphenol decelerates bladder cancer growth involving apoptosis and cell cycle arrest in N-butyl-N-(4hydroxybutyl) nitrosamine-induced experimental animal model. Journal of Functional Foods, 36, $1-8$.

Larsen, F. J., Weitzberg, E., Lundberg, J. O., Ekblom, B. (2010). Dietary nitrate reduces maximal oxygen consumption while maintaining work performance in maximal exercise. Free Radical Biology and Medicine, 48(2), 342-347.

Li, L., Shao, J., Zhu, X., Zhou, G., Xu, X. (2013). Effect of plant polyphenols and ascorbic acid on lipid oxidation, residual nitrite and $\mathrm{N}$-nitrosamines formation in dry-cured sausage. International Journal of Food Science \& Technology, 48(6), 1157-1164.

Li, L., Wang, P., Xu, X., Zhou, G. (2012). Influence of various cooking methods on the concentrations of volatile $\mathrm{N}$-nitrosamines and biogenic amines in dry-cured sausages. Journal of Food Science, 77(5), C560-C565. 
Lundberg, J. O., Larsen, F. J., Weitzberg, E. (2011). Supplementation with nitrate and nitrite salts in exercise: a word of caution. Journal of Applied Physiology, 111(2), 616-617.

Marriott, N. G., Lechowich, R. V., Pierson, M. D. (1981). Use of nitrite and nitrite-sparing agents in meats: A review. Journal of Food Protection, 44(11), 881-885.

McKnight, G. M., Smith, L. M., Drummond, R. S., Duncan, C. W., Golden, M. I. N. H., Benjamin, N. (1997). Chemical synthesis of nitric oxide in the stomach from dietary nitrate in humans. Gut, 40(2), 211-214.

Mejborn, H., Hansen, M., Biltoft-Jensen, A., Christensen, T., Ygil, K. H., \& Olesen, P. T. (2019). Suggestion for a subdivision of processed meat products on the Danish market based on their content of carcinogenic compounds. Meat science, 147, 91-99.

Mikuška, P., Večeřa, Z. (2003). Simultaneous determination of nitrite and nitrate in water by chemiluminescent flow-injection analysis. Analytica chimica acta, 495(1), 225-232.

Mirvish, S. S. (1986). Effects of vitamins C and E on N-nitroso compound formation, carcinogenesis, and cancer. Cancer, 58(S8), 1842-1850.

Oliveira, C. P., Gloria, M. B. A., Barbour, J. F., Scanlan, R. A. (1995). Nitrate, nitrite, and volatile nitrosamines in whey-containing food products. Journal of agricultural and food chemistry, 43(4), 967-969.

Ozel, M. Z., Gogus, F., Yagci, S., Hamilton, J. F., Lewis, A. C. (2010). Determination of volatile nitrosamines in various meat products using comprehensive gas chromatography-nitrogen chemiluminescence detection. Food and Chemical Toxicology, 48(11), 3268-3273.

Österdahl, B. G. (1988). Volatile nitrosamines in foods on the Swedish market and estimation of their daily intake. Food Additives \& Contaminants, 5(4), 587-595.

Özdestan, Ö., Üren, A. (2010). Gıdalarda nitrat ve nitrit. Akademik Glda, 8(6), 35-43.

Öztürk, B., Serdaroğlu, M., Ergezer, H. (2015). Et ve Et Ürünlerinde Nitrit-Nitrat; Kullanım Avantajları, Yasal Sınırlamalar ve Güncel Alternatif Yaklaşımlar. Akademik Gıda. 13(3), 257264.

Park, J. E., Seo, J. E., Lee, J. Y., \& Kwon, H. (2015). Distribution of seven N-nitrosamines in food. Toxicological research, 31(3), 279.

Qiu, Y., Chen, J. H., Yu, W., Wang, P., Rong, M., \& Deng, H. (2017). Contamination of Chinese salted fish with volatile N-nitrosamines as determined by QuEChERS and gas chromatographytandem mass spectrometry. Food chemistry, 232, 763-769.

Rabie, M. A., Siliha, H., El-Saidy, S., El-Badawy, A. A., Malcata, F. X. (2010). Effects of $\gamma$ irradiation upon biogenic amine formation in Egyptian ripened sausages during storage. Innovative food science \& emerging technologies, 11(4), 661-665.

Rattray, C., \& Cochran, J. (2014). Combined Determination of 1, 4-Dioxane and Nitrosamine Contaminants in Drinking Water. Lit. Cat.\# EVAN1922A-UNV, http://www. restek. com/Technical-Resources/Technical-Library/Environmental/env_EVAN1922-UNV. 
Rywotycki, R. (2003). Meat nitrosamine contamination level depending on animal breeding factors. Meat science, 65(1), 669-676.

Rywotycki, R. (2002). The effect of selected functional additives and heat treatment on nitrosamine content in pasteurized pork ham. Meat science, 60(4), 335-339.

Seo, J. E., Park, J. E., Lee, J. Y., \& Kwon, H. (2016). Determination of seven N-nitrosamines in agricultural food matrices using GC-PCI-MS/MS. Food Analytical Methods, 9(6), 1595-1605.

Song, I. H., Kim, W. J., Jo, C., Ahn, H. J., Kim, J. H., Byun, M. W. (2003). Effect of modified atmosphere packaging and irradiation in combination on content of nitrosamines in cooked pork sausage. Journal of food protection, 66(6), 1090-1094.

Stepanov, I., Sebero, E., Wang, R., Gao, Y. T., Hecht, S. S., \& Yuan, J. M. (2014). Tobacco-specific $\mathrm{N}$-nitrosamine exposures and cancer risk in the Shanghai cohort study: Remarkable coherence with rat tumor sites. International journal of cancer, 134(10), 2278-2283.

Toldrá, F., Hui, Y. (2014). Dry-Fermented Sausages and Ripened Meats: An Overview. Handbook of Fermented Meat and Poultry, 1-6.

Venkatesan, A. K., Pycke, B. F., \& Halden, R. U. (2014). Detection and occurrence of N-nitrosamines in archived biosolids from the targeted national sewage sludge survey of the US Environmental Protection Agency. Environmental science \& technology, 48(9), 5085-5092.

Wang, Y., Li, F., Zhuang, H., Chen, X., Li, L., Qiao, W., \& Zhang, J. (2015). Effects of plant polyphenols and $\alpha$-tocopherol on lipid oxidation, residual nitrites, biogenic amines, and $\mathrm{N}$ nitrosamines formation during ripening and storage of dry-cured bacon. LWT-Food Science and Technology, 60(1), 199-206.

Wilkens, L. R., Kadir, M. M., Kolonel, L. N., Nomura, A. M., Hankin, J. H. (1996). Risk factors for lower urinary tract cancer: the role of total fluid consumption, nitrites and nitrosamines, and selected foods. Cancer Epidemiology and Prevention Biomarkers, 5(3), 161-166.

Yuan, Y., Meng, W., Yutian, M., Fang, C., Xiaosong, H. (2015). Determination of Eight Volatile Nitrosamines in Meat Products by Ultrasonic Solvent Extraction and Gas Chromatography-Mass Spectrometry Method. International Journal of Food Properties, 18(6), 1181-1190.

Yurchenko, S., Mölder, U. (2007). The occurrence of volatile N-nitrosamines in Estonian meat products. Food Chemistry, 100(4), 1713-1721.

Yurchenko, S., Mölder, U. (2006). Volatile N-nitrosamines in various fish products. Food Chemistry, 96 (2), 325-333. 